\title{
ON THE SELF-SIMILAR HEAT BOUNDARY LAYER PROBLEMS IN MAGNETOHYDRODYNAMICS
}

\author{
V. KREMENETSKY \\ Institute of Physics of Latvian University \\ Miera 32, LV-2169, Salaspils, Latvia \\ E-mail: vladesal.lv
}

Received September 28, 2001; revised November 12, 2001

\begin{abstract}
Usually all self-similar heat boundary layer problems in presence of magnetic field are solved neglecting the Joule heat, created by current, induced in fluid by interaction of velocity and magnetic field. But the analysis of this heat shows that its influence to the temperature field is very important. For vertical flows it is impossible to find self-similar solution of boundary layer problems due to the Joule heat influence in temperature field. For horizontal flows only two self-similar boundary layer problems can be formulated: flow near the critical point in magnetic field with the neutral point and in the transverse steady magnetic field.
\end{abstract}

\section{INTRODUCTION}

The large attention is paid to the heat boundary layer in the magnetic field due to wide practical needs. To solve this type of problems the self-similar approximation is used. This method allows to reduce partial differential equations to the ordinary equations [2]:

In most cases formulating of that type problems the Joule heat dissipation is neglected. This Joule heat is created by electric current induced in moving fluid by magnetic field. But is this neglect correct? 


\section{MAGNETOHYDRODYNAMICS PROBLEMS}

Motion of electrically conducting fluid in magnetic field with heat convection is determined by the system of differential equations [2]:

a) the fluid motion equation

$$
(\boldsymbol{V} \cdot \nabla) \boldsymbol{V}=-\frac{1}{\rho} \operatorname{grad} p+\mathrm{v} \nabla^{2} \boldsymbol{V}-\beta T \boldsymbol{g}+\frac{1}{\rho} \boldsymbol{j} \times \boldsymbol{B},
$$

b) the energy equation

$$
\boldsymbol{V} \cdot \operatorname{grad} T=\chi \nabla^{2} T+\frac{|\boldsymbol{j}|^{2}}{\sigma \rho c_{\nu}}
$$

c) The Maxwell equation

$$
j=\frac{1}{\mu_{0}} \operatorname{rot} B
$$

d) The Ohm equation for moving environment

$$
j=\sigma(\boldsymbol{E}+\boldsymbol{V} \times \boldsymbol{B}),
$$

e) solenoidality conditions for velocity, electric and magnetic fields

$$
\operatorname{div} \boldsymbol{V}=0, \quad \operatorname{div} \boldsymbol{j}=0, \quad \operatorname{div} \boldsymbol{B}=0 .
$$

Here $\nabla^{2}=\frac{\partial}{\partial x^{2}}+\frac{\partial}{\partial y^{2}}, \sigma-$ electrical conductivity, $\rho-$ density, $c_{\nu}-$ constant of specific heat, $\chi=\frac{\lambda}{\rho c_{\nu}}$ - specific temperature conductivity, $\lambda$ - specific heat conductivity, $\mu_{0}=4 \pi \cdot 10^{-7} \mathrm{H} / \mathrm{m}$.

Applying the rotor operation to the equation (2.1) we obtain the fluid motion equation without pressure

$$
\operatorname{rot}(\operatorname{rot} \boldsymbol{V} \times \boldsymbol{V})=\nu \nabla^{2} \operatorname{rot} \boldsymbol{V}-\beta \operatorname{rot} \mathrm{T} \boldsymbol{g}+\frac{1}{\mu_{0}} \operatorname{rot}(\operatorname{rot} \boldsymbol{B} \times \boldsymbol{B}),
$$

and from (2.2) and (2.3) we get the induction equation

$$
\nabla^{2} \boldsymbol{B}=-\sigma \mu_{0} \operatorname{rot}(\boldsymbol{V} \times \boldsymbol{B}) .
$$


In two-dimensional plane case it is possible to introduce 3 stream functions [1]: the hydrodynamic stream function $\psi$ :

$$
u=\frac{\partial \psi}{\partial y}, \quad \mathrm{v}=-\frac{\partial \psi}{\partial x},
$$

the electric stream function $\psi_{1}$ :

$$
j_{x}=\frac{\partial \psi_{1}}{\partial y} \quad j_{y}=-\frac{\partial \psi_{1}}{\partial x},
$$

the magnetic stream function $\psi_{2}$ :

$$
B_{x}=\frac{\partial \psi_{2}}{\partial y}, \quad B_{y}=-\frac{\partial \psi_{2}}{\partial x} .
$$

First, we substitute (2.6) and (2.8) into induction equation (2.5) after converting it to co-ordinate form. In result we obtain

$$
\nabla^{2} \psi_{2}=-\sigma \mu_{0}\left(\frac{\partial \psi}{\partial x} \frac{\partial \psi_{2}}{\partial y}-\frac{\partial \psi}{\partial y} \frac{\partial \psi_{2}}{\partial x}\right)+K
$$

The Maxwell equation gives us

$$
j_{z}=\frac{1}{\mu_{0}}\left(\frac{\partial B_{y}}{\partial x}-\frac{\partial B_{x}}{\partial y}\right)=-\frac{1}{\mu_{0}} \nabla^{2} \psi_{2}
$$

or, using (2.9),

$$
j_{z}=-\frac{1}{\mu_{0}} \nabla^{2} \psi_{2}=\sigma\left(\frac{\partial \psi}{\partial x} \frac{\partial \psi_{2}}{\partial y}-\frac{\partial \psi}{\partial y} \frac{\partial \psi_{2}}{\partial x}\right)-K .
$$

Next, we transform fluid motion equation (2.4) using (2.6) - (2.8) and consider them in domains without external electric current sources in fluid. The result is:

$$
\begin{aligned}
& \frac{\partial \psi}{\partial x} \frac{\partial}{\partial y} \nabla^{2} \psi-\frac{\partial \psi}{\partial y} \frac{\partial}{\partial x} \nabla^{2} \psi+\nu \nabla^{2}\left(\nabla^{2} \psi\right) \\
& =\beta g\left(\frac{\partial T}{\partial x} \cos \gamma-\frac{\partial T}{\partial y} \cos \alpha\right) \\
& \quad+\frac{1}{\rho \mu_{0}}\left(\frac{\partial \psi_{2}}{\partial x} \frac{\partial}{\partial y} \nabla^{2} \psi_{2}-\frac{\partial \psi_{2}}{\partial y} \frac{\partial}{\partial x} \nabla^{2} \psi_{2}\right) .
\end{aligned}
$$

The energy equation can be written as:

$$
\frac{\partial \psi}{\partial y} \frac{\partial T}{\partial x}-\frac{\partial \psi}{\partial x} \frac{\partial T}{\partial y}=\chi \nabla^{2} T+\frac{1}{\sigma}\left[\left(\frac{\partial \psi_{1}}{\partial y}\right)^{2}+\left(\frac{\partial \psi_{1}}{\partial x}\right)^{2}+\frac{1}{\mu_{0}^{2}}\left(\nabla^{2} \psi_{2}\right)^{2}\right] .
$$


To ensure that the problem is 2-dimensional here is assumed that gravity force is oriented in $x-y$ plane. $\alpha$ and $\gamma$ are angles between gravity vector $\boldsymbol{g}$ and $O x$ and $O y$ axes, respectively.

Usually, 2 types of heat boundary layers are considered: vertical (boundary layer is parallel to the gravity force) and horizontal (boundary layer is perpendicular to the gravity force).

Also, we use non-induction approximation. In this case we take into account induced electric currents, but not their magnetic fields. For this purpose we shall find magnetic stream function as a series by Batchelor's parameter [1]

$$
\psi_{2}=\sum_{n=0} \beta^{n} \psi_{2 n},
$$

$\beta=\mu_{0} \sigma \nu-$ Batchelor's parameter.

On Earth this parameter is about $10^{-6} \div 10^{-7}$ and we can use only two first terms of this series: $\psi_{20}$ - external magnetic field, and $\psi_{21}$-induced currents.

Induction equation $(2.9)$ gives for these terms $(K=0)$ :

$$
\begin{aligned}
\nabla^{2} \psi_{20} & =0 \\
\nabla^{2} \psi_{2} & =\nabla^{2} \psi_{21}=-\sigma \mu_{0}\left(\frac{\partial \psi}{\partial x} \frac{\partial \psi_{20}}{\partial y}-\frac{\partial \psi}{\partial y} \frac{\partial \psi_{20}}{\partial x}\right) .
\end{aligned}
$$

To construct self-similar boundary layer solution in both vertical and horizontal cases we shall use these functions:

$$
\begin{array}{r}
\nabla^{2}=\frac{\partial^{2}}{\partial y^{2}}, \psi=A x^{k} f(\eta), \psi_{2}=D x^{\gamma} f_{2}(\eta), \\
T=C x^{q} \Theta(\eta), \eta=y / B x^{p} .
\end{array}
$$

Now let us to investigate each type of boundary layer separately.

\subsection{Vertical flows}

The case $\alpha=0, \gamma=\pi / 2$.

Here we have the following system of differential equations:

a) the fluid motion equation

$$
\begin{aligned}
\frac{\partial \psi}{\partial x} \frac{\partial^{3} \psi}{\partial y^{3}} & -\frac{\partial \psi}{\partial y} \frac{\partial^{3} \psi}{\partial x \partial y^{2}}+\nu \frac{\partial^{4} \psi}{\partial y^{4}} \\
& =\beta g \frac{\partial T}{\partial y}-\frac{\sigma}{\rho \mu_{0}}\left(\frac{\partial \psi_{20}}{\partial x} \frac{\partial}{\partial y}\left(\frac{\partial \psi}{\partial x} \frac{\partial \psi_{20}}{\partial y}-\frac{\partial \psi}{\partial y} \frac{\partial \psi_{20}}{\partial x}\right)\right. \\
& \left.-\frac{\partial \psi_{20}}{\partial y} \frac{\partial}{\partial x}\left(\frac{\partial \psi}{\partial x} \frac{\partial \psi_{20}}{\partial y}-\frac{\partial \psi}{\partial y} \frac{\partial \psi_{20}}{\partial x}\right)\right) .
\end{aligned}
$$


b) The energy equation

$$
\frac{\partial \psi}{\partial y} \frac{\partial T}{\partial x}-\frac{\partial \psi}{\partial x} \frac{\partial T}{\partial y}=\chi \frac{\partial^{2} T}{\partial y^{2}}+\frac{\sigma}{\rho c_{\nu} \mu_{0}}\left(\frac{\partial \psi}{\partial x} \frac{\partial \psi_{20}}{\partial y}-\frac{\partial \psi}{\partial y} \frac{\partial \psi_{20}}{\partial x}\right)^{2}
$$

Substituting (2.10) into (2.11) and (2.12) we obtain

$$
\begin{aligned}
& \frac{A^{2}}{B^{3}} x^{2 k-3 p-1}\left(k f-p \eta f^{\prime}\right) f^{\prime \prime \prime} \\
& \quad-\frac{A^{2}}{B^{3}} x^{2 k-3 p-1} f^{\prime}\left((k-2 p) f^{\prime \prime}-p \eta f^{\prime \prime \prime}\right)+\frac{\nu A}{B^{4}} x^{k-4 p} f^{I V} \\
& \quad=\frac{\sigma}{\rho} \frac{A D^{2}}{B^{2}} x^{2 \gamma+k-2 p-2}\left[( \gamma f _ { 2 0 } - p \eta f _ { 2 0 } ^ { \prime } ) \left[\left(k f-p \eta f^{\prime}\right) f_{20}^{\prime}\right.\right. \\
& \left.\quad-f^{\prime}\left(\gamma f_{20}-p \eta f_{20}^{\prime}\right)\right]^{\prime}-f_{20}^{\prime}(k+\gamma-p-1)\left[\left(k f-p \eta f^{\prime}\right) f_{20}^{\prime}\right. \\
& \left.\left.\quad-f^{\prime}\left(\gamma f_{20}-p \eta f_{20}^{\prime}\right)\right]+p \eta f_{20}^{\prime}\left[\left(k f-p \eta f^{\prime}\right) f_{20}^{\prime}-f^{\prime}\left(\gamma f_{20}-p \eta f_{20}^{\prime}\right)\right]^{\prime}\right] \\
& \quad+\frac{\beta g C}{B} x^{q-p} \Theta^{\prime}, \\
& \frac{A C}{B} x^{k-p+q-1}\left(q \Theta-p \eta \Theta^{\prime}\right) f^{\prime}-\frac{A C}{B} x^{k-p+q-1}\left(k f-p \eta f^{\prime}\right) \Theta^{\prime} \\
& \quad=\chi \frac{C}{B^{2}} x^{q-2 p} \Theta^{\prime \prime}-\frac{\sigma}{\rho c_{\nu} \mu_{0}} \frac{A^{2} D^{2}}{B^{2}} x^{2 k+2 \gamma-2 p-2}\left(f_{20}^{\prime}\left(k f-p \eta f^{\prime}\right)\right. \\
& \left.\quad-f^{\prime}\left(\gamma f_{20}-p \eta f_{20}^{\prime}\right)\right)^{2} .
\end{aligned}
$$

For self-similarity the orders of variable $x$ of all terms in (2.13) and (2.14) should be equal. This condition gives us the system of equalities:

$$
\begin{aligned}
& 2 k-3 p-1=k-4 p=q-p=2 \gamma+k-2 p-2 \\
& \quad=k-p+q-1=q-2 p=2 k-2 \gamma-2 p-2, \\
& p=1-k, k=\gamma, q=4 k-3 .
\end{aligned}
$$

This system has no solution if $k>0$ (only in this case we can transform Laplace operator $\nabla^{2}=\frac{\partial^{2}}{\partial x^{2}}+\frac{\partial^{2}}{\partial y^{2}}$ to $\nabla^{2}=\frac{\partial^{2}}{\partial y^{2}}$ ). This means that it is impossible to construct the self-similar solution for problems of this type. If we try to solve this system without the last term (the Joule heat), we obtain: $p=1-k, \gamma=k, q=4 k-3$. Putting these expressions into the energy equation, we can see, that order of $x$ of all terms is $6 k-5$, but order of Joule heat is $6 k-4$. This means that far from zero of the co-ordinate system the Joule heat influence to the temperature field dominates. 


\subsection{Horizontal flows}

The case $\alpha=\pi / 2, \gamma=0$.

The system of differential equations takes the form:

a) the fluid motion equation

$$
\begin{aligned}
\frac{\partial \psi}{\partial x} & \frac{\partial^{3} \psi}{\partial y^{3}}-\frac{\partial \psi}{\partial y} \frac{\partial^{3} \psi}{\partial x \partial y^{2}}+\nu \frac{\partial^{4} \psi}{\partial y^{4}} \\
= & \beta g \frac{\partial T}{\partial x}-\frac{\sigma}{\rho \mu_{0}}\left(\frac { \partial \psi _ { 2 0 } } { \partial x } \frac { \partial } { \partial y } \left(\frac{\partial \psi}{\partial x} \frac{\partial \psi_{20}}{\partial y}\right.\right. \\
& \left.\left.\quad-\frac{\partial \psi}{\partial y} \frac{\partial \psi_{20}}{\partial x}\right)-\frac{\partial \psi_{20}}{\partial y} \frac{\partial}{\partial x}\left(\frac{\partial \psi}{\partial x} \frac{\partial \psi_{20}}{\partial y}-\frac{\partial \psi}{\partial y} \frac{\partial \psi_{20}}{\partial x}\right)\right)
\end{aligned}
$$

b) energy equation:

$$
\frac{\partial \psi}{\partial y} \frac{\partial T}{\partial x}-\frac{\partial \psi}{\partial x} \frac{\partial T}{\partial y}=\chi \frac{\partial^{2} T}{\partial y^{2}}+\frac{\sigma}{\rho c_{v} \mu_{0}}\left(\frac{\partial \psi}{\partial x} \frac{\partial \psi_{20}}{\partial y}-\frac{\partial \psi}{\partial y} \frac{\partial \psi_{20}}{\partial x}\right)^{2}
$$

Putting (2.18) into (2.15) and (2.16) gives:

$$
\begin{aligned}
& \frac{A^{2}}{B^{3}} x^{2 k-3 p-1}\left(k f-p \eta f^{\prime}\right) f^{\prime \prime \prime} \\
& \quad-\frac{A^{2}}{B^{3}} x^{2 k-3 p-1} f^{\prime}\left((k-2 p) f^{\prime \prime}-p \eta f^{\prime \prime \prime}\right)+\frac{\nu A}{B^{4}} x^{k-4 p} f^{I V} \\
& \quad=\frac{\sigma}{\rho} \frac{A D^{2}}{B^{2}} x^{2 \gamma+k-2 p-2}\left[( \gamma f _ { 2 0 } - p \eta f _ { 2 0 } ^ { \prime } ) \left[\left(k f-p \eta f^{\prime}\right) f_{20}^{\prime}\right.\right. \\
& \left.\quad-f^{\prime}\left(\gamma f_{20}-p \eta f_{20}^{\prime}\right)\right]^{\prime}-f_{20}^{\prime}(k+\gamma-p-1)\left[\left(k f-p \eta f^{\prime}\right) f_{20}^{\prime}\right. \\
& \left.\left.\quad-f^{\prime}\left(\gamma f_{20}-p \eta f_{20}^{\prime}\right)\right]+p \eta f_{20}^{\prime}\left[\left(k f-p \eta f^{\prime}\right) f_{20}^{\prime}-f^{\prime}\left(\gamma f_{20}-p \eta f_{20}^{\prime}\right)\right]^{\prime}\right] \\
& \quad+\beta g C x^{q-1}\left(q \Theta-p \eta \Theta^{\prime}\right), \\
& \frac{A C}{B} x^{k-p+q-1}\left(q \Theta-p \eta \Theta^{\prime}\right) f^{\prime}-\frac{A C}{B} x^{k-p+q-1}\left(k f-p \eta f^{\prime}\right) \Theta^{\prime} \\
& \quad=\chi \frac{C}{B^{2}} x^{q-2 p} \Theta^{\prime \prime}-\frac{\sigma}{\rho c_{\nu} \mu_{0}} \frac{A^{2} D^{2}}{B^{2}} x^{2 k+2 \gamma-2 p-2}\left(f_{20}^{\prime}\left(k f-p \eta f^{\prime}\right)\right. \\
& \left.\quad-f^{\prime}\left(\gamma f_{20}-p \eta f_{20}^{\prime}\right)\right)^{2} .
\end{aligned}
$$

Self-similarity conditions are:

$$
\begin{aligned}
& 2 k-3 p-1=k-4 p=q-1 \\
& =2 \gamma+k-2 p-2=k-p+q-1 \\
& =q-2 p=2 k+2 \gamma-2 p-2,
\end{aligned}
$$


This system have only one solution (for $k>0$ ):

$$
k=1, \quad \gamma=1, \quad p=0, \quad q=2 .
$$

In this case it is possible to formulate two self-similar boundary layer problems for the flow near the critical point:

a) in transverse steady magnetic field (Fig. 1,a);

b) in magnetic field with neutral point (Fig. 1,b).
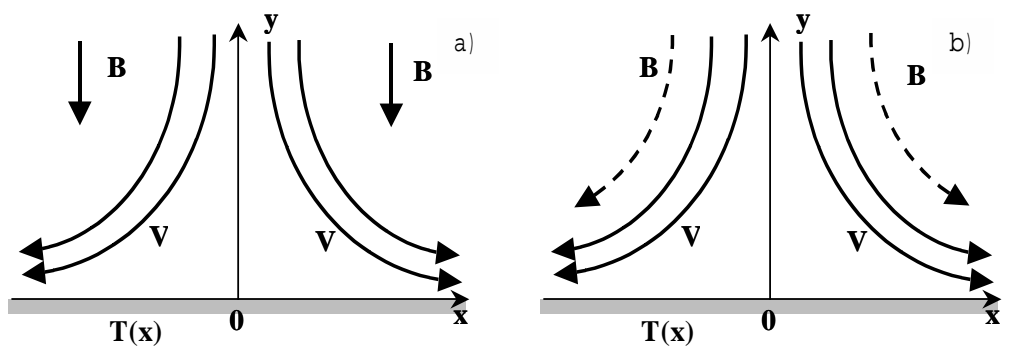

Figure 1. Schemes of fluid flow and magnetic fields: a) flow near the critical point in transverse steady magnetic field; b) the flow near the critical point in magnetic field with neutral point.

These configurations of magnetic field are obtained from the equation

$$
\nabla^{2} \psi_{20}=0 \Rightarrow f_{20}(\eta)=C_{1} \eta+C_{2}
$$

and

$$
\begin{aligned}
& B_{x 0}=\frac{\partial \psi_{20}}{\partial y}=\frac{D C_{1}}{B} x^{2 y-1} \\
& B_{y 0}=-\frac{\partial \psi_{20}}{\partial x}=-\frac{D C_{1}}{B}(2 \gamma-1) y x^{2 \gamma-1}-D C_{2} \gamma x^{\gamma-1}
\end{aligned}
$$

For $\gamma=1$ :

a) $C_{1}=0, C_{2}=1$ - the transverse steady vertical magnetic field:

$B_{x 0}=0, B_{y 0}=-D$;

b) $C_{1}=1, C_{2}=0$ - the magnetic field with neutral point:

$$
B_{x 0}=\frac{D}{B} x, B_{y 0}=-\frac{D}{B} y \text {. }
$$


We will use these dimensionless parameters: $\operatorname{Pr}=\frac{A B}{\chi}-$ Prandtl number $(A B=\nu), G r=\frac{\beta g C B^{4}}{\nu A}-$ Grashof number, $H a^{2}=\frac{\sigma D^{2} B^{2}}{\rho \nu}-$ Hartmann number, $E c=\frac{V^{2}}{c_{v} t^{0}}-$ Eckert number. Then we have

$$
\frac{\sigma}{\rho c_{v} \mu_{0} \chi} \frac{A^{2} D^{2}}{C}=H a^{2} \operatorname{Pr} E c .
$$

The Eckert number is used here formally and it is not connected with interpretation given, for example, in [3].

\subsection{Flow near the critical point in the transverse steady magnetic field}

In this case the stream functions are:

$$
\psi=A x f(\eta), \quad \psi_{2}=D x f_{20}(\eta), \quad T=C x^{2} \Theta(\eta), \eta=y / B, f_{20}(\eta)=1
$$

Equations:

$$
\begin{aligned}
& f^{I V}+f f^{\prime \prime \prime}-f^{\prime} f^{\prime \prime}=2 G r \Theta-H a^{2} f^{\prime \prime} \\
& \operatorname{Pr}\left(2 \Theta f^{\prime}-f \Theta^{\prime}\right)=\Theta^{\prime \prime}-H a^{2} \operatorname{Pr} E c f^{\prime 2}
\end{aligned}
$$

Boundary conditions:

$$
f(0)=0 ; f^{\prime}(0)=0 ; f^{\prime \prime}(\infty)=0 ; f^{\prime}(\infty)=1 ; \Theta(0)=1 ; \Theta(\infty)=0 .
$$

But if we put boundary conditions into the energy equation, we obtain:

$$
\begin{aligned}
\eta=\infty: \operatorname{Pr}\left(2 \Theta(\infty) f^{\prime}(\infty)-f(\infty) \Theta^{\prime}(\infty)\right)= & \Theta^{\prime \prime}(\infty)-H a^{2} \operatorname{Pr} E c f^{2}(\infty) \\
& \Rightarrow \Theta^{\prime \prime}(\infty)=H a^{2} \operatorname{Pr} E c
\end{aligned}
$$

This contradicts with the boundary condition $\Theta^{\prime \prime}(\infty)=0$, if we try to find smooth solution for this problem. This contradiction is because velocity and magnetic field interact not only in boundary layer but in whole fluid outside the boundary layer. This Joule heat induced in the whole fluid force us to find another boundary condition for $\Theta^{\prime \prime}(\infty)$. 


\subsection{Flow near the critical point in the magnetic field with the neu-} tral point

In this problem the stream functions are:

$$
\psi=A x f(\eta), \quad \psi_{2}=D x f_{20}(\eta), \quad T=C x^{2} \Theta(\eta), \eta=y / B, f_{20}(\eta)=\eta
$$

Equations:

$$
\begin{aligned}
& f^{I V}+f f^{\prime \prime \prime}-f^{\prime} f^{\prime \prime}=2 G r \Theta-H a^{2}\left(-\eta^{2} f^{\prime \prime}+\eta f^{\prime}-f\right), \\
& \operatorname{Pr}\left(2 \Theta f^{\prime}-f \Theta^{\prime}\right)=\Theta^{\prime \prime}-H a^{2} \operatorname{Pr} E c\left(f-\eta f^{\prime}\right)^{2} .
\end{aligned}
$$

Boundary conditions:

$$
f(0)=0 ; f^{\prime}(0)=0 ; f^{\prime \prime}(\infty)=0 ; f^{\prime}(\infty)=1 ; \Theta(0)=1 ; \Theta(\infty)=0 .
$$

In this case all boundary conditions do not contradict with equations. This is because the formal topology of velocity streamlines and the magnetic field are the same outside the boundary layer and electric current induces only in boundary layer, where velocity and streamlines of magnetic field intersect.

But attempts to obtain the numerical solution fail. This is because the solution of the pure hydrodynamic problem gives that fluid velocity far from boundary layer is $\mathrm{v}=-D y+C$ and $C$ is not zero. Interaction of such velocity and the magnetic field creates Joule heat far from heating plane and this situation contradicts with the boundary condition $\Theta(\infty)=0$.

\section{CONCLUSION}

It is impossible to formulate self-similar heat boundary layer problem in the magnetic field for vertical flows with Joule dissipation. But also we have no rights to neglect this induced heat because its influence is very strong.

Two problems can be formulated for self-similar horizontal flows: flow near the critical point in the magnetic field with the neutral point and in the transverse steady magnetic field. But both of them could not be solved due to contradictions between equations and natural boundary conditions.

\section{REFERENCES}

[1] A. Bartulis, V. Kremenetskii and E.V. Shcherbinin. Obshchii metod postroenija avtomodel'nych reshenii dlia ploskich MGD techenii. Magnitnaja gidromechanika, 34(2), $109-128$, 1998. (in Russian) 
[2] V.V. Bojarevich, J.Zh. Freiberg, E.I. Shilova and E.V. Shcherbinin. Elektrovikhrevye techenija. Riga, Zinatne, 1985. (in Russian)

[3] G. Shlikhting. Teorija pogranichnogo sloja. M., 1974. (in Russian)

\section{Apie automodelinius pakraščio sluoksnio šilumos uždavinius magnetinëje hidrodinamikoje}

V. Kremenetsky

Paprastai visi automodeliniai pakraščio sluoksnio šilumos uždaviniai, esant magnetiniam laukui, yra sprendžiami ignoruojant Džiaulinę šilumą, kurią sukuria srovė indikuota skysčio greičio ir magnetinio lauko sąveikos. Tačiau šios šilumos įtaka į temperatūrini lauką labai svari. Vertikaliesiems srautams neįmanoma rasti automodelinio sprendinio dèl Džaulinès šilumos įtakos i temperatūrinį lauką. Horizontaliesiems srautams gali būti suformuluoti tik du automodeliniai pakraščio sluoksnio šilumos uždaviniai: tekèjimas netoli kritinio taško magnetiniame lauke, turinčiame neutralųji tašką ir tekejjimas stabiliame magnetiniame lauke. 